\title{
Changes in the anterior segment of the eye following uncomplicated pars plana vitrectomy. A review
}

\author{
Adam Kopecky a,b, Jan Nemcansky ${ }^{a}$
}

Pars plana vitrectomy is currently the most common technique used in retinal surgery. Although primarily involving the posterior segment of the eye it also affects the anterior segment. As this is a less published topic, the aim of this paper was to review the literature on changes in the anterior segment after uncomplicated pars plana vitrectomy using data based literature search.

The conclusions are that even in otherwise ophthalmologically healthy patients, complications may occur in the anterior segment. Surgeons need to pay utmost attention in glaucoma patients and in those with endothelial insufficiency who are at highest risk of complications. He/she must also correctly plan a potential cataract surgery if not already done earlier. From the literature, most of the changes in the anterior segment after uncomplicated PPV are found to be temporary.

Key words: pars plana vitrectomy, anterior segment, corneal endothelium, ultrasound biomicroscopy, ophthalmology

Received: October 14, 2018; Revised: February 3, 2019; Accepted: April 3, 2019; Available online: April 17, 2019 https://doi.org/10.5507/bp.2019.014

(c) 2019 The Authors. This is an open access article licensed under the Creative Commons Attribution License (https://creativecommons.org/licenses/by/4.0/).

${ }^{a}$ Clinic of Ophthalmology, University Hospital Ostrava, Czech Republic

${ }^{b}$ First Faculty of Medicine, Charles University Prague, Czech Republic

Corresponding author: Adam Kopecky, e-mail:adam.kopecky@fno.cz

\section{INTRODUCTION}

Pars Plana Vitrectomy (PPV) is a dominant surgical technique used for posterior segment eye surgery. The safety of this surgical method has been improving and the spectrum of indications has been expanding.

The aim of this review was to examine the available literature and briefly assess how PPV can influence the anterior segment.

\section{SCLEROTOMIES}

It has been shown that the introduction of ports into the pars plana region alone is a major interference with the integrity of the eyeball. Vitreous prolapse in the port is a commonly reported situation and although this is anticipated to be more common in large sclerotomies, it has also been reported after $25 \mathrm{G}$ vitrectomy. The largest study to evaluate prolapse after pars plana vitrectomy (20G) found that prolapse is worse in places of light and instrument ports, where only $15 \%$ of all ports were prolapse free in contrast to $68.3 \%$ infusion ports which were clear $^{1}$. Vitreous prolapse was also confirmed in a small sample after $25 \mathrm{G}$ PPV, with a clinical recommendation to perform anterior vitrectomy at the beginning of surgery ${ }^{2}$.

The healing of sclerotomy is the subject of several studies. It can be said that sclerotomy in $25 \mathrm{G}$ vitrectomy heals much faster than sclerotomy in $20 \mathrm{G}$ vitrectomy.
However, according to some studies, the sclerotomy tunnel is evident on the first day after surgery, but in sutureless systems, such as $23 \mathrm{G}$ or $25 \mathrm{G}$ pars plana vitrectomy, the number of sclerotomies detected after 30 days is significantly lower. In the $25 \mathrm{G}$ group, however, conjunctival blebs were more frequently found above the sclerotomy sites, and surprisingly more frequent vitreous prolapse. However, the conclusion of Guttfleisch et al was that one month after the surgery, virtually no differences can be found between the respective techniques ${ }^{3}$.

It should be noted that, according to another study, sclerotomy and vitreous prolapse may be the potential basis for future complications, especially the development of peripheral cracks at the site of peripheral vitreous traction ${ }^{4}$.

Vitreous prolapse (incanceration) into the ports, however, may occur in virtually all types of vitrectomy, including the most modern $27 \mathrm{G}$ vitrectomy. Tosi et al examined patients after PPV with flap ports, but they found no noticeable difference compared to non-valve ports ${ }^{5}$.

\section{CORNEA AND ITS THICKNESS}

Historically older work described statistically confirmed changes on the corneal surface, including astigmatism $^{6}$. On the other hand, this study also showed a gradual stabilization of the finding with time. The more recent work of Domniz et al. confirmed this trend - chang- 
es occur shortly after surgery and soon stabilize, and one month after surgery the keratometry values return to preoperative values ${ }^{7}$.

Apropos comparison of various techniques, for example Citrik et al. confirmed the difference between $25 \mathrm{G}$ vitrectomy and classical $23 \mathrm{G}$ vitrectomy. There were no statistically significant changes in corneal parameters in the $25 \mathrm{G}$ group, whereas in the $23 \mathrm{G}$ group the changes were apparent one day and one month after surgery, while their return to preoperative values occurred up to 3 months after surgery ${ }^{8}$.

In another study, Pentacam scans unambiguously confirmed changes in the anterior segment after pars plana vitrectomy with a silicone oil filling - early changes are seen in the ventricular angle, in the deep anterior chamber and in the corneal thickness ${ }^{9}$. Again, however, the return to preoperative values occurred over time (after one month).

The said corneal thickness was examined in several studies. For example, Hager et al. ${ }^{10}$ described corneal thickening in a group of PPV patients.

Hamoudi et al. ${ }^{11}$ followed patients on months 3 and 12 postoperatively. They reported a statistically significant corneal thickening in the third month, but during the final control, these values were again at baseline levels.

Although another study reported short-term corneal thickening, the condition changed one month after surgery, suggesting that opinions and conclusions regarding this issue are heterogeneous ${ }^{12}$.

\section{CORNEAL ENDOTHELIUM}

Changes in the cornea and mainly in the number of endothelial cells is well known in cataract surgery. With longer duration of phacoemulsification, the density of the corneal endothelium is reduced ${ }^{13}$. The literature in this regard for PPV is sparse. Studies have been conducted that compared PPV alone with combined surgery (vitrectomy and phacoemulsification at one time), with the result that the difference in the degree of decrease in endothelial cell density was minimal or slightly against the combined procedure ${ }^{14}$. On the other hand, Hamoudi et al. found virtually no statistical difference between vitrectomy performed in combination with phacoemulsification or alone (before or after vitrectomy) (ref. ${ }^{11}$ ). No difference was found in the level of decrease in endothelial cell density or corneal thickness in either group. This study, like others, describes a general decrease of about $15-20 \%$ in the density of endothelial cells ${ }^{11}$.

In relation to PPV with silicone oil, for example, Legler et al reported a change in endothelial cell density within the range of $22.9 \%+/-13.3 \%$ (ref. ${ }^{15}$ ). In another study, Cinar et al. concluded that both gas and silicone filling may damage the corneal endothelium, and pseudophakic eyes are more prone to this damage ${ }^{16}$.

The basic requirement for prevention of possible complications is a healthy endothelium ${ }^{16}$. This has a relation to length of surgery. Endothelial cell loss was found to be higher in groups with gas tamponade and silicone oil tamponade in pseudophakic patients (natural lens is a protective factor) (ref. $\left.{ }^{16}\right)$.

Another study evaluated the changes in endothelial cell morphology - however, in the long run, endothelial loss was not significant in silicone oil tamponade, and morphological changes occur, even if there is no direct contact of silicone oil with the endothelium ${ }^{17}$. Naturally, cases of loss of endothelium in tamponade complication - i.e. presence of silicone oil in the anterior chamber - are also described in the literature ${ }^{18-20}$.

Interestingly, an older study by Mittl et al. compared pseudophakic and aphakic patients. This confirmed, albeit in a narrow group of patients, that aphakic patients had a significantly higher endothelial loss than pseudophakic patients $^{21}$.

The literature also provides support for the artificial intraocular lens acting as a valuable protection in PPV. This was described by Goezinne et al. in different patients with silicone oil tamponade - the greatest loss was recorded in the group with additional phacoemulsification and in combined surgeries ${ }^{22}$.

\section{ANTERIOR CHAMBER DEPTH}

Anterior chamber depth and chamber angle openness were identified in one study as a mechanism for increasing intraocular pressure after pars plana vitrectomy ${ }^{23}$. In a smaller sample study, however, no changes in the anterior chamber parameters were found, apart from lens thickness changes ${ }^{24}$. This fact was confirmed by another, larger, study by Marigo et al. ${ }^{25}$.

Studies that have explored this issue commonly use ultrasound biomicroscopy. The possible changes in the anterior segment are put in context with gas tamponade ${ }^{26}$. It is also clear that impacts on the anterior segment are higher in combined surgery ${ }^{27}$. Taking into account the conclusions of other papers confirming the changes in lens parameters - this is clinically predictable since the relationship of cataract formation to pars plana vitrectomy is confirmed by studies, even independently of the size of the port used ${ }^{28,29}$.

Chamber fluid misdirection syndrome, i.e. a malignant glaucoma, is one of the most serious complications in ocular surgery. Although PPV is considered a method for treating misdirection, rare cases have been described when pars plana vitrectomy caused misdirection ${ }^{30}$. In addition, cases are described in the literature where misdirection recurred after PPV (ref. ${ }^{31}$ ).

This is related to the view that vitrectomy may be beneficial in patients with an extremely shallow anterior chamber. This supposition was supported for example by Zhang et al, who measured inter alia the anterior chamber depth in glaucoma patients after pars plana vitrectomy and lensectomy. He demonstrated a deepening of the anterior chamber ${ }^{32}$.

Seo et al. compared groups of patients, who underwent phacovitrectomy, pars plana vitrectomy alone and 
lensectomy alone. The anterior chamber deepening was evident in the phacovitrectomy and lensectomy groups, and was more pronounced in the first group. In the vitrectomy-only group, shallowing of the anterior chamber was observed, which could be attributed to the postoperative natural cataract formation ${ }^{33}$.

The most common reason for affecting the anterior segment is therefore the expansion of the gas tamponade that pushes the structures forward into the anterior chamber. Rotation of the ciliary body is less known and less dependent on the chosen tamponade, and may cause an elevation of the intraocular pressure.

An intraocular lens or intact posterior capsule in pseudophakic patients are considered protective factors in PPV. Conversely, mostly affecting the anterior segment is seen in patients undergoing "phacovitrectomy", a combination of cataract surgery and PPV at one time.

\section{INTRAOCULAR PRESSURE}

Intraocular pressure and its elevation are among the most commonly observed "complications" of pars plana vitrectomy.

In one study, postoperative hypotonia was found in only $8.1 \%$ of patients but, the study group was diverse in terms of indication diagnoses ${ }^{34}$.

However, sufficient support can be found in the literature for the incidence of elevated intraocular pressure. In one large group of patients operated on using the pars plana vitrectomy technique for retinal detachment elevation of intraocular pressure occurred postoperatively in $46 \%$ of patients. Myopia, pseudophakia and high preoperative intraocular pressure have been identified as risk factors. Silicone oil tamponade was identified as an additional risk ${ }^{35}$.

Another study confirmed pseudophakia to be a risk factor for elevation of intraocular pressure and the authors suggested that unmanaged elevation of intraocular pressure may even lead to glaucomatous damage to the optic nerve ${ }^{23}$. Open-angle glaucoma was identified as another risk factor. This paper also mentions the mechanism of elevation of intraocular pressure after pars plana vitrectomy in pseudophakic eyes, namely that the absence of vitreous increases the concentration of oxygen within the eye ball. In phakic eyes, this increased oxygen concentration is the cause of the frequent occurrence of nuclear cataracts. In aphakic and pseudophakic eyes, however, higher oxygen concentrations penetrate into the anterior segment, which can result in oxidative damage to the trabeculae, which may subsequently lead to an elevation of intraocular pressure. As a conclusion, this study emphasizes the importance of identification and subsequent management of patients with elevated intraocular pressure.

In the long run, the intraocular pressure is described in the literature as stable after PPV and in various surgical indications of pars plana vitrectomy ${ }^{36,37}$.

This aside, some studies describe the late onset of elevation of intraocular pressure. For example, Toyokawa et al. found it in $4.2 \%$ of patients, with no relation to sex, indications, or type of vitrectomy used ${ }^{38}$.

\section{LENS CHANGES}

Cataract formation after pars plana vitrectomy has been repeatedly documented in the literature ${ }^{39,40}$. The percentage of patients with cataract formation after pars plana vitrectomy depends on the type of the surgical technique. At least mild lens changes are commonly observed after 20G PPV (96\%), and less frequently after $23 \mathrm{G}$ and $25 \mathrm{G}$ PPV (72\%) (ref. $\left.{ }^{40}\right)$. In eyes after PPV, nuclear and posterior subcapsular cataracts are very common ${ }^{40,41}$. Posterior subcapsular cataract is typical for eyes with silicone oil filling, while nuclear opacification can occur with any type of tamponade ${ }^{42}$. Transient feather-like cataract is often observed after intraocular gas tamponade.

There are several theories about the pathophysiology of the cataract formation after PPV. Transport systems for maintaining the water and electrolyte balance are localized in the outer lens fibers. Some authors suggest that gas and silicone oil tamponade affect the function of $\mathrm{NaK}$ ATPase $^{42,43}$. This leads to swelling of the lens fibers.

Another theory proposes that oxidative stress plays an important role in nuclear cataract formation. Vitreous is a natural barrier for oxygen. After PPV the partial oxygen is pressure may be elevated and this leads to increased oxygen stress. Opacification is caused by oxidation of structural lens proteins ${ }^{42}$. As it is possible to measure the oxygenation of retinal vessels and arteries, we know that oxygen saturation is higher in non-diabetes patients after PPV and this lasts for 52 weeks ${ }^{44}$.

We should also take in consideration the effect of PPV on pseudophakic eyes. It is proven that posterior capsule opacification is more rapid in patients after combined surgery (PPV + phacoemulsification) and after PPV in pseudophakic eye than in patients after cataract surgery alone ${ }^{45}$.

When indicating cataract surgery after PPV, the surgeon should take into consideration that optical biometry is superior to ultrasound biometry in eyes after PPV $\left(\right.$ ref. $\left.^{46}\right)$. Also, although cataract formation is definitely connected with PPV, according to Do et al., there is a dearth of randomized trials proving that cataract surgery further improves vision in patients after PPV ( ref. $^{47}$ ).

From the clinical point of view, the surgeon should always take into consideration whether it is useful to plan the cataract surgery before the PPV or to perform the PPV alone.

\section{CONCLUSION}

This review has attempted to summarize the current literature on the effect of PPV on the anterior segment. This is a relatively neglected topic, and study samples are often small. Even in otherwise ophthalmologically healthy patients, complications may occur in the anterior seg- 
ment. Surgeon need to pay utmost attention in glaucoma patients and in those with endothelial insufficiency, who have the highest risk of complications. He/she must also correctly plan a potential cataract surgery if not already done earlier. From the literature, most of the changes in the anterior segment after uncomplicated PPV are considered temporary.

\section{Search strategy and selection criteria}

We searched PubMed and Web of Science databases for scientific articles on the presented topic. As there is a relative dearth of literature, we used as many published articles with related terms as possible. Some articles were based on a very small samples. Our goal was to find the most relevant information for clinical practice, to sum up the known and documented clinical impact of anterior segment changes after PPV.

Author contributions: AK: literature search, manuscript writing; JN: literature search, literature interpretation.

Conflict of interests statement: The authors state that there are no conflicts of interest regarding the publication of this article.

\section{REFERENCES}

1. Zheng $Y$, Lin $H$, Liu W, Wang D, Huang S. Vitreous Incarceration in Patients Undergoing Second 20-Gauge Pars Plana Vitrectomy for Recurrent Retinal Detachment. ISRN Ophthalmology 2011;2011:456191.

2. Shimada H, Nakashizuka H, Hattori T, et Mori R, Mizutani Y, Yuzawa $M$. Clear visualization of anterior vitreous incarceration into cannulae during 25-gauge vitrectomy in eyes with asteroid hyalosis. Eur Ophthalmol 2012;22(2):293-5.

3. Gutfleisch M, Dietzel M, Heimes B, Spital G, Pauleikhoff D, Lommatzsch $A$. Ultrasound biomicroscopic findings of conventional and sutureless sclerotomy sites after 20-, 23-, and 25-G pars plana vitrectomy. Eye (Lond) 2010;24(7):1268-72.

4. Sabti K, Kapusta M, Mansour M, Overbury O, Chow D. Ultrasound biomicroscopy of sclerotomy sites: the effect of vitreous shaving around sclerotomy sites during pars plana vitrectomy. Retina 2001;21(5):464-8.

5. Tosi GM, Malandrini A, Cevenini G, Neri G, Marigliani D, Cerruto A, Gianni V. Vitreous incarceration in sclerotomies after valved 23-, 25or 27-gauge and nonvalved 23- or 25-gauge macular surgery. Retina (Philadelphia, Pa) 2017;37(10):1948-55.

6. Wirblauer C, Hoerauf H, Roider J, Lagua H. Corneal shape changes after pars plana vitrectomy. Graefes Arch Clin Exp Ophthalmol 1998;236(11):822-8.

7. Domniz YY, Cahana M, Avni I. Corneal surface changes after pars plana vitrectomy and scleral buckling surgery. J Cataract Refract Surg 200;27(6):868-72.

8. Citirik M, Batman C, Bicer T, Zilelioglu O. Keratometric alterations following the 25 -gauge transconjunctival sutureless pars plana vitrectomy versus the conventional pars plana vitrectomy. Clin Exp Optom 2009;92(5):416-20.

9. Çalik B, Öztürk M, Serdarogullari H, Elçioğlu M. Evaluation of anterior segment parameters using pentacam in silicone oil-injected patients after pars plana vitrectomy. Indian J Ophthalmol 2013;61(11):621-5.

10. Hager A, Loge $K$, Kutschan A, Wiegand W. The effect of cataract and vitreoretinal surgery on central corneal thickness and corneal hysteresis. Klin Monbl Augenheilkd 2008;225(3):207-11.

11. Hamoudi H, Christensen UC, La Cour M. Corneal endothelial cell loss and corneal biomechanical characteristics after two-step sequential or combined phaco-vitrectomy surgery for idiopathic epiretinal membrane. Acta Ophthalmol 2017:95(5):493-7.

12. Watanabe A, Shibata T, Takashina H, Ogawa S, Tsuneoka H.
Changes in corneal thickness following vitreous surgery. Clinical Ophthalmology (Auckland, NZ) 2012;6:1293-6.

13. Lucena DR, Ribeiro MS, Messias A, Bicas HE, Scott IU, Jorge R Comparison of corneal changes after phacoemulsification using BSS Plus versus Lactated Ringer's irrigating solution: a prospective randomised trial. Br J Ophthalmol 2011;95(4):485-9.

14. Koushan K, Mikhail M, Beattie A, Ahuja N, Liszauer A, Kobetz L, Farrykhyar F, Martin JA. Corneal endothelial cell loss after pars plana vitrectomy and combined phacoemulsification-vitrectomy surgeries. Can J Ophthalmol 2017;52(1):4-8.

15. Legler U, Seiberth V, Knorz MC, Jung E, Liesenhoff H. Loss of corneal endothelial cells following pars plana vitrectomy and silicone oil implantation. Fortschr Ophthalmol 1990;87(3):290-3.

16. Cinar E, Zengin MO, Kucukerdonmez C. Evaluation of corneal endothelial cell damage after vitreoretinal surgery: comparison of different endotamponades. Eye 2015;29(5):670-4.

17. Farrahi F, Feghhi M, Ostadian F, Alivand A. Pars plana vitrectomy and silicone oil injection in phakic and pseudophakic eyes; corneal endothelial changes. J Ophthalmic Vis Res 2014;9(3):310-3.

18. Sternberg P, Jr, Hatchell DL, Foulks GN, Landers MB. The effect of silicone oil on the cornea. Arch Ophthalmol 1985;103:90-4.

19. Federman JL, Schubert HD. Complications associated with the use of silicone oil in 150 eyes after retina-vitreous surgery. Ophthalmology 1988;95:870-6.

20. Pang MP, Peyman GA, Kao GW. Early anterior segment complications after silicone oil injection. Can J Ophthalmol 1986;21:271-5.

21. Mittl RN, Koester CJ, Kates MR, Wilkes E. Endothelial cell counts following pars plana vitrectomy in pseudophakic and aphakic eyes. Ophthalmic Surg 1989;20(1):13-6.

22. Goezinne F, Nuijts RM, Liem AT, Lundgvist IJ, Berendschot TJ, Cals DW, Hendrikse F, La Heij EC. Corneal endothelial cell density after vitrectomy with silicone oil for complex retinal detachments. Retina 2014;34(2):228-36.

23. Wu L, Berrocal MH, Rodriguez FJ, Maia M, Morales-Canton V, Figueroa M, Serrano M, Roca JA, Arévalo JF, Navarro R, Hernández $\mathrm{H}$, Salinas S, Romero R, Alpizar-Alvarez N, Chico G. Intraocular pressure elevation after uncomplicated pars plana vitrectomy: results of the Pan American Collaborative Retina Study Group. Retina 2014;34(10):1985-9.

24. Ghomi Z, Ghassemi F. Changes in Anterior Segment Parameters Following Pars Plana Vitrectomy Measured by Ultrasound Biomicroscopy (UBM). Medical Hypothesis, Discovery and Innovation in Ophthalmology 2017;6(1):14-8.

25. Marigo Fde A, Zisman M, Nehemy MB, Marigo PV. Ultrasound biomicroscopy in the comparison of the anterior segment morphometry before and after pars plana vitrectomy. Arq Bras Oftalmol 2006;69(6):919-22.

26. Ünsal E, Eltutar K, Karini B, Kizilay O. Assessment of Anterior Segment Changes in Pseudophakic Eyes, Using Ultrasonic Biomicroscopic Imaging, after Pars Plana Vitrectomy with Silicone Oil or Gas Tamponade. J Ophthalmol 2016;2016:8303792.

27. Park SP, Ahn JK, Lee GH. Morphologic changes in the anterior segment after phacovitrectomy for proliferative diabetic retinopathy. J Cataract Refract Surg 2009;35(5):868-73.

28. Ghomi Z, Ghassemi F. Changes in Anterior Segment Parameters Following Pars Plana Vitrectomy Measured by Ultrasound Biomicroscopy (UBM). Medical Hypothesis, Discovery and Innovation in Ophthalmology 2017;6(1):14-8.

29. Feng $\mathrm{H}$, Adelman RA. Cataract formation following vitreoretinal procedures. Clin Ophthalmol 2014;8:1957-65.

30. Balaggan KS, Laidlaw DA. Aqueous misdirection syndrome after pars plana vitrectomy for retinal detachment. Retin Cases Brief Rep 2008;2(1):73-5

31. Dave P, Rao A, Senthil S, Choudhari NS. Recurrence of aqueous misdirection following pars plana vitrectomy in pseudophakic eyes. BMJ Case Rep 2015;2015. pii: bcr2014207961. doi: 10.1136/bcr-2014207961

32. Zhang Z, Zhang S, Jiang X, Qiu S, Wei Y. Surgical outcomes of 23-gauge transconjunctival pars plana vitrectomy combined with lensectomy for glaucomatous eyes with extremely shallow anterior chamber and cataract. BMC Ophthalmol 2016;16:2.

33. Seo S, Seong MC, Lim HW, Kang MH, Cho HY. The Changes of Anterior Chamber Depth, Axial Length, Refractive Errors after Combined Vitrectomy. J Korean Ophthalmol Soc 2013;54(7):1032-7. 
34. Gupta N, Punjabi OS, Steinle NC, Singh RP. Rate of hypotony following 25-gauge pars plana vitrectomy. Ophthalmic Surg Lasers Imaging Retina 2013;44(2):155-9.

35. Jabbour E, Azar G, Antoun J, Kourie HR, Abdelmassih Y, Jalkh A. Incidence and Risk Factors of Ocular Hypertension following Pars Plana Vitrectomy and Silicone Oil Injection. Ophthalmologica 2018;240(3):129-34. doi: 10.1159/000489792

36. Fujikawa M, Sawada O, Kakinoki M, Sawada T, Kawamura H, Ohji M. Long-term intraocular pressure changes after vitrectomy for epiretinal membrane and macular hole. Graefes Arch Clin Exp Ophthalmo 2014;252(3):389-93.

37. Muether PS, Hoerster R, Kirchhof B, Fauser S. Course of intraocular pressure after vitreoretinal surgery: is early postoperative intraocular pressure elevation predictable? Retina 2011;31(8):1545-52.

38. Toyokawa N, Kimura H, Matsumura M, Kuroda S. Incidence of late-onset ocular hypertension following uncomplicated pars plana vitrectomy in pseudophakic eyes. Am J Ophthalmol 2015;159(4):727-32.

39. Chung CP, Hsu SY, Wu WC. Cataract formation after pars plana vitrectomy. Kaohsiung J Med Sci 2001;17(2):84-9.

40. Feng $\mathrm{H}$, Adelman RA. Cataract formation following vitreoretinal procedures. Clin Ophthalmol 2014;8:1957-65.
41. Chang MA, Parides MK, Chang S, Braunstein RE. Outcome of phacoemulsification after pars plana vitrectomy. Ophthalmology 2002;109(5):948-54.

42. Petermeier K, Szurman P, Bartz-Schmidt UK, Gekeler F. Pathophysiology of cataract formation after vitrectomy. Klin Monbl Augenheilkd 2010;227(3):175-80.

43. Hsuan JD, Brown NA, Bron AJ, Patel CK, Rosen PH. Posterior subcapsular and nuclear cataract after vitrectomy. J Cataract Refract Surg 2001;27:437-44.

44. Šín M, Chrapek O, Karhanová M, Šínová I, Špačková K, Langová K, Řehák J. The effect of pars plana vitrectomy and nuclear cataract on oxygen saturation in retinal vessels, diabetic and non-diabetic patients compared. Acta Ophthalmol 2016;94(1):41-7.

45. Jun JH, Kim KS, Chang SD. Nd: YAG Capsulotomy after Phacoemulsification in Vitrectomized Eyes: Effects of Pars Plana Vitrectomy on Posterior Capsule Opacification. J Ophthalmol 2014;2014:840958.

46. Shousha MA, Yoo SH. Cataract surgery after pars plana vitrectomy. Curr Opin Ophthalmol 2010;21(1):45-9.

47. Do DV, Gichuhi S, Vedula SS, Hawkins BS. Surgery for post-vitrectomy cataract. Cochrane Database Syst Rev 2013;12(12):CD006366. 